This is an Accepted Manuscript of an article published by Taylor \& Francis Group in Qualitative Research in Psychology on 17 Dec 2018, available online: http://www.tandfonline.com/10.1080/14780887.2018.1545066

GENOGRAMS IN RESEARCH

\title{
Genograms in Research: Participants' Reflections of the Genogram Process
}

\section{Published in Qualitative Research in Psychology}

\section{Joanne H. Alexander, Jane E.M. Callaghan, Lisa C. Fellin}

\begin{abstract}
The genogram is a visual, symbolic representation of multiple generations of a family, structured in much the same way as a family tree. Genograms emerged within systemic family therapy as an assessment and intervention tool but, in their ability to generate rich data, they are gaining traction as a research tool. While the benefits of genograms in therapeutic practice have been well documented, the literature exploring them as a research method is limited. This paper aims to contribute to this knowledge, by considering participants' experiential reflections of constructing their genograms, a process they engaged in as part of a broader study which explored the intergenerational transmission of family violence. We illustrate that while genograms generated powerful qualitative data, they also had unintended therapeutic and transformative effects on participants which transcended the interview room. We consider the ethical complexities of using genograms as a qualitative method, and make recommendations for future research.
\end{abstract}

\section{Introduction}

The genogram is a visual representation of multiple generations of a family, structured like a family tree (see Fig. 1 for example) (Iverson et al., 2005). Genograms can include the symbolic depiction of relatively objective 'factual' information, such as family structure, sociodemographics, deaths, disease and illness, as well as subjective information including relational dynamics, stressful life events, behaviours and culture (Castoldi et al., 2006; Mackay, 2015; Watts \& Shrader, 1998). Genograms emerged within systemic family therapy as an assessment and intervention tool (Mackay, 2015; McGoldrick, 2016; McGoldrick et al., 2008), but are used in social work (Hartman, 1995; Piedra, 2016), medicine and health care (Leonidas \& Santos, 2015; Werner-Lin \& Gardner, 2009), and in education (Crowell, 2017; Hardy \& Laszloffy, 1995; Keiley et al., 2002). In their ability to generate rich and immediate data, they are gaining traction as a research tool (Iverson et al., 2005; McGoldrick et al., 2008; Watts \& Shrader, 1998).

Figure 1. Example Genogram

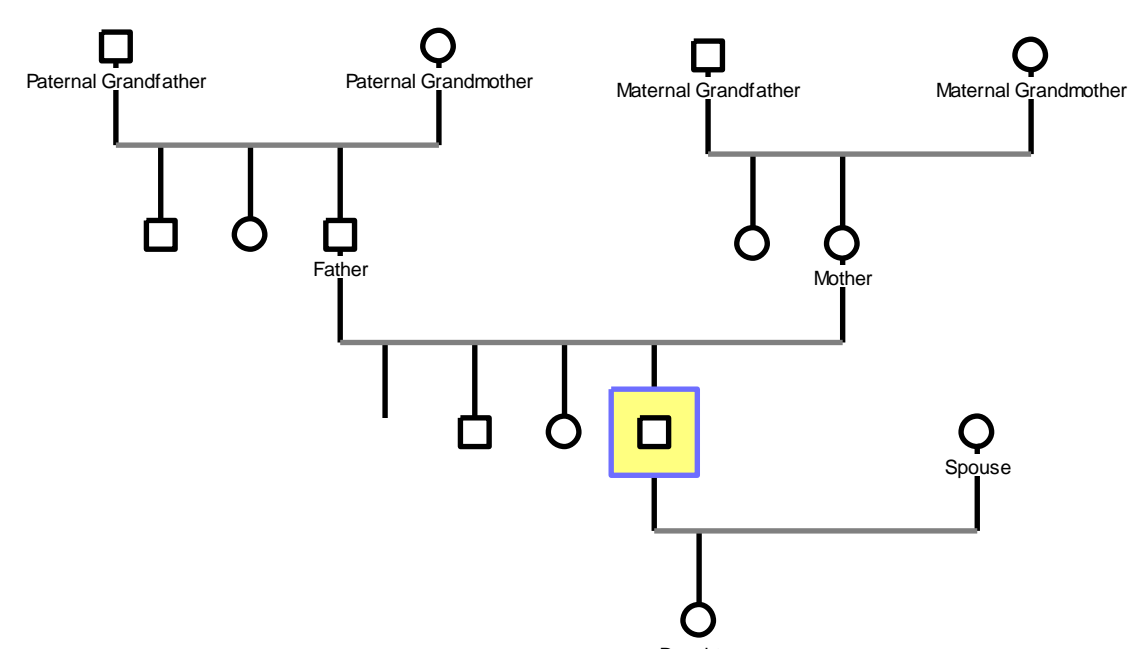


The benefits of using genograms in therapeutic practice have been well documented. Genograms can facilitate clients' deeper, more nuanced explorations of family and, as various authors have suggested, when co-constructed with clients, genograms can support engagement and enhance the therapeutic alliance (Altshuler, 1999; Burley, 2014; Mackay, 2015). The ability of the genogram to develop rapport has also been observed by researchers. Reflecting on their use of visual methods in conjunction with interviews, Rempel et al., (2007) maintained that co-constructed or 'interactive' genograms and ecomaps (a visual method which depicts the individual/family's broader social relationships), were particularly powerful in the research process because they aided rapport and promoted '...a relational process between researcher and participant' (p.403). In sensitive research that invites participants to disclose information of a personal nature, the development of rapport is essential, and data collection dependent on it. However, as research may only involve a one-off encounter between the researcher and participant, encouraging the development of rapport introduces an ethical dimension, the likes of which is not present in the therapeutic process. In therapy, for example, sessions can run in the mid-long term and endings are regarded as an important part of the therapeutic process, and are carefully negotiated by the therapist. Managing rapport and the close of contact do not necessarily feature as integral components of research training. As such, tools which develop rapport, such as the genogram, may require careful consideration and planning by researchers, to ensure they can work sensitively with participants' (and their own) investments in the research relationship, and the feelings of abandonment that might emerge from the ending of that alliance.

As they provide 'systemic contextualisation', representation of the individual-in-family, genograms can support engagement with social constructionist understandings of reality, moving away from more realist perspectives (Iverson et al., 2005). However, because standard genogram construction typically represents ancestral descent through biological or spousal relations (Tasker \& Granville, 2011), it has received criticism for its tendency towards excluding the depiction of counter-hegemonic 'family' compositions, such as non-kin, extra-familial, same-sex or adopted families (Singh, 2009). As it presumes western ideologies of 'family' in its biological preoccupation, it automatically disables the representation of different cultural conceptualisations of 'family' (Singh, 2009; Watts-Jones, 1997). Watts-Jones (1997) proposes an African American genogram, a genogram that transcends the assumption of 'family' as solely biological. Other authors too, have espoused ways that standard construction and notation might be adapted to better represent diverse family compositions and cultural contexts in sensitive and nuanced ways (Milewski-Hertlein, 2001; Tasker \& Granville, 2011; Congress, 1994). Ensuring that genograms are capable of depicting participants' conceptualisations of family is an issue for researchers wanting to use them as a visual method, and one requiring careful consideration to avoid eliding or marginalising particular family structures.

In research, genograms have been used to study a diverse range of intergenerational aspects. Watts and Shrader (1998) found that genograms provided an effective visual summary of their data, and functioned as a reflexive tool for participants and researchers during follow-up interviews. Rempel et al., (2007) also attest to the value of genograms in research, and note their ability to facilitate 
researchers' understandings of participants' families. As a visual methodology, genograms may be particularly beneficial in sensitive research because they can function as an 'intermediary artifact' enabling participants to indirectly express 'difficult memories and powerful emotions' through their drawings (Prosser, 2013, p.188). As with other visual methods, genograms can promote both nonverbal and verbal reflections, enabling exploration of conscious or non-conscious issues and experiences, and uncovering experiences and memories previously unarticulated (Mitchell et al., 2011). Thus, together with interviews, as a visual tool, genograms can support the generation of rich data, both in raw visual form, and by facilitating verbal accounts.

Genograms can be a co-construction of several family members, but they tend to be individually constructed. Even when they are created on an individual basis, genograms represent and, therefore, involve (by proxy) immediate and extended family members and (ex-)intimate partners who are not consulted in how they are represented, nor privy to the consent process (Fontes, 1998; Langford, 2000). Because of this, using genograms in research raises a number of ethical challenges that need to be carefully considered and managed. Furthermore, as genograms incorporate details about a particular group of people, it may increase the risk of identification, (McGoldrick et al., 2008) and this in itself is a major disadvantage of using genograms as a research tool.

As illustrated here, genograms present a myriad of ethical challenges for researchers wanting to implement them. The value of genograms in therapeutic practice and in training has been well reported, and their utility in research is increasingly being recognised. However, literature exploring genograms as a method of qualitative research and, in particular, participants' experiences of the genogram process in research contexts, is limited. In light of their capacity to affect change in people's perceptions when used in therapy, it is crucial that we gain a better understanding of their potential impact on research participants. This paper aims to contribute to the literature on genograms in qualitative research, by considering a small group of participants' experiential reflections of engaging in the genogram process.

\section{Research Methods}

\section{Participants}

Participants were recruited as part of the first author's doctoral research (supervised by J.C \& L.F) which explored women's accounts of the intergenerational transmission of family violence. This study included a small and specific sample of women who identified as having experienced family violence in multiple generations. Fifteen in-depth individual semi-structured interviews were conducted with nine women aged 22-50 (see appendix 1 for participant table). The study adopted a pluralist qualitative approach (Frost \& Nolas, 2011) and incorporated genograms, ecomaps, and individual semi-structured interviews. This paper focuses on interview data directly relating to participants' experiential reflections of constructing and engaging with their genograms.

Women were recruited via two UK-based domestic violence (DV) agencies and professional networks. Inclusion criteria for participation related to safeguarding, and required women to be immediately safe' (Sullivan \& Cain, 2004) and away from violence at the point of interview and, where relevant, to be deemed by agencies working with them as such. At the time of interview, the majority of 
participants were either receiving or had historically received support from specialist domestic violence services $(n=8)$, only 1 woman had never received any specialist DV support. Two women were residing in refuge at the time of interview. Others were attending counselling, or had access to less formalised support systems such as church or peer support groups where they were used to talking about their experiences of violence and their intimate relationships.

\section{Recruitment}

Recruitment was a relatively slow process, and some women who were initially interested decided not to participate, largely due to concerns around anonymity. Safeguarding issues also cropped up during recruitment, for example, one woman wanted to bring along her new partner to the interview, and another said that she would have to ask permission from her family before she agreed to take part. These examples illustrate the complexities in family violence research, and show the potential vulnerability and safeguarding issues (for researcher and participant) that family research - involving family by proxy, might entail. During the recruitment phase, the first author contacted a total of 12 organisations, nationally and locally, that were either dedicated DV or family services. The recruited cohort consisted of 8 White British women and 1 White Italian woman. As this sample comprised white and heterosexual women only, it is limited in its capacity to reflect the diversity of the target population.

\section{Ethical Considerations}

This project received ethical approval from The University of Northampton's Social Sciences Research Ethics Committee. Researchers adhered to the ethical standards of the British Psychological Society (BPS, 2009). We intend to discuss the ethical complexities of this project in greater depth in a separate publication, but outline the key ethical considerations, here.

To ensure that potential participants were fully informed, (first author) met with each potential participant in person to explain the nature of the research, genogram construction, their involvement, and ethical rights and protections.

As this project required participants to share material of a highly personal nature, there was a risk of inducing secondary traumatisation and emotional upset in participants. There are risks associated with recollecting traumatic incidents (Carter-Visscher et al., 2007), such as violence, and of genogram production (Crowell, 2017). However, various authors indicate that while interviews might induce a low level of distress, quickly afterwards, participants typically recall their experiences positively (Bunnell \& Legerski, 2010; Carter-Visscher et al., 2007). The interviewer (first author) had prior training and experience of working with families affected by violence in a research capacity, was cognizant of the complex safeguarding issues inherent in research of this nature, and was experienced in utilising a distress protocol. Following participation, where necessary, participants were signposted to relevant agencies, or referred to organisations directly for onward support. One woman was signposted to a rape counselling service, another to a DV counselling service, and additional support was sought for 1 woman accessing DV services. 
During participation, mindful that the material could be emotionally challenging, women were offered breaks at appropriate points in the research process, or where signs of upset were visible. Women were also offered the opportunity to break down genogram construction/interview over a number of sessions. It was envisaged that this would not only help to minimise distress by giving women a break between sessions, if they wanted it, but it would also help to generate a greater level of complexity in the data, representative of family and intimate partner violence. Four women attended once, four others attended twice, and one woman attended on three occasions.

To ensure that participants did not interpret intergenerational trends in their genograms as fixed and unchangeable, or as prophetic of their own futures, (first author) was transparent about the limitations of genograms from the outset. Participants were informed that their genograms provide only one perspective, a symbolic representation of a given time, and that they are limited in their capacity to fully and holistically reflect the complexities, contexts or transience of relationships over time.

\section{Genogram Construction and Interviews}

To ensure participants had a good understanding of how to create genograms, they were shown examples and provided with an explanation of how to construct them, and informed of how they would be used to guide the interview. Participants were also shown an electronic example of a genogram (created using GenoPro 2011 software) to give them an idea of how their hand-drawn genograms would look after they had been electronically re-created and anonymised by the researcher. The study was designed so that genogram construction would be, to a certain extent, informed by the GenoPro software, and the symbols made available to participants were determined by its legend which included 36 'emotional relationships' such as 'harmony', 'close', 'distant', 'conflict' etc. In order to represent changes to family structure and relationships over time, the women were invited to construct two genograms each, one 'Retrospective', depicting family composition and relational dynamics in childhood, and the other 'Active', representing family at the time of interview. Typically, the women identified experiences of violence in 4 generations of their families.

(First author) provided step-by-step support to help participants represent relationships technically accurately, for example ensuring that a line was drawn vertically to represent a child rather than horizontally, which could represent a marriage. Despite this, the technical construction elicited some anxiety in several of the women. In these cases, genograms were produced as a co-construction, and the researcher drew them as participants talked through who they wanted to include and what they perceived the relationships to be. To ensure the researcher accurately captured the information, they echoed participants' instructions both before and as they drew to enable participants the opportunity to correct or make changes. A member-checking phase was also implemented after interview which enabled participants to contact the researcher with amendments to their electronic genograms. Because of the issues in interpreting genograms (Rohrbaugh et al., 1992), and visual methods generally (Banks, 2012), genograms were used in this study as a graphic elicitation tool, and were not themselves analysed. While interviews focused on family violence, questions relating to genogram construction were also explored. This allowed the documentation of women's experiences of engagement in the genogram process. 


\section{Data Preparation and Thematic Analysis}

Interviews were audio-recorded and transcribed verbatim, and genograms were electronically recreated. Transcripts and genograms were anonymised, and all names, locations and identifying information were either replaced with pseudonyms or omitted. Women's transcripts were coded for reflections related to the genogram method, including experiences of construction, limitations, and feelings about depicting families/relationships. For the purposes of this paper, all textual data relating to genograms was extracted from the women's transcripts/reflections and thematically analysed (Braun \& Clarke, 2006). Cross-coding formed part of the doctoral research, and during preliminary analysis all three authors coded the same extract of a 39-page transcript, and discussed observations and coding in supervisory meetings.

\section{Participant Reflections}

Thematic analysis of women's reflections on the genogram process identified three key themes: 'Reenvisioning Family, Reframing Self'; 'Simplifying the Complex: The Limitations of Labels'; and 'Genograms as Transformative'. The first theme offers insight into how genogram production functioned as a reflexive tool for participants, facilitating renewed understandings of themselves and their families. The second, illustrates participants' struggles in attempting to symbolise their histories of violence and highly complex family relationships in genogram formation. The final theme describes how some participants used their genograms outside the research space, to connect to family or to instigate changes in their relationships. We discuss these findings below, considering the value of genograms in the data collection process, and the ethical implications they bring to the research context.

\section{Re-Envisioning Family, Reframing Self}

In this theme, we explore how genograms shifted the women's conceptualisations of family and self. Renewed understandings were expressed by some participants as positive and empowering, but by others as surprising. We consider the capacity of genograms for inducing new insights and 'altered perceptions' (Hartman, 1995), and discuss the implications for research.

Constructing her genogram enabled one of the women (Naomi) to see her family from a more reflective and balanced perspective:

Int: [...] what does it feel like to kind of put your family history in a drawing?

Naomi: [...] We keep ourselves to ourselves sort of thing and everything bottled up, which is like our main problem. I know that from experience, that's our main problem. So to see it down flat it does make me think that's a lot more violence and hostility, anger and unsolved problems throughout the family. I don't think it's just one side of the family, which is quite interesting really. Because I've always thought it was from my [paternal] gran. [...] I always thought it was coming from her, coming down that way. [...]But to see that it's also on the other side of the family is very interesting.

The symbolic depiction of the family's relational dynamics enabled Naomi to view her family system in its entirety, and to see how other members had been touched by violence. It also facilitated an 
understanding that violence was perhaps more embedded within the family system than she had previously understood, or perhaps, than had been expressed in the family narrative. As Naomi alludes, genograms might make the individual's lived version of the story visible for the first time. Understanding that violence originates from maternal as well as paternal relations, makes space for her to alter her identification of paternal relations as the source of all familial discontent. In this sense, Naomi's genogram allowed her to move polarised stories of family violence, which individualise and blame certain members, towards a more integrative account which considers violence and victimhood across the whole family system.

Like Naomi, Georgia's genogram helped to illuminate other family members who had suffered violence as she had:

Int: Can I ask you, Georgia, what did it feel like doing this [motions towards drawings] and what does it feel like seeing all your family relationships like this?

Georgia: It felt weird because it shows that, on that drawing really, it wasn't just me that suffered from abuse in the past; it has been other family members as well. So it's like it's [transmitted] [...] because it seems whatever way you look at it on my mum's side and my dad's side, it looks like there's always been abuse there throughout the years.

Quotes above exemplify how participants' genograms helped to uncover or validate other family members' experiences of violence. As a visual method, they generated information that verbal accounts alone may not have produced. In making particular aspects of family visible, they illuminate distinctions between lived and narrated stories, and the gaps - the aspects/persons that participants elide from depictions or accounts (Rempel et al., 2007), the information that they do/do not know, and what they can/cannot articulate. The key purpose of genograms in systemic therapy is to elicit new insights by highlighting relational patterns across the system. Quotes indicate that genograms had a similar therapeutic effect on research participants, and this signals a blurring of the boundaries between clinical and research impact. Indeed, one participant directly remarked on the likeness between genogram production and therapy:

Int: What did it feel like doing [your genogram] and what does it feel like looking at it?

Jenny: A bit like a huge counselling session, that's how I felt this morning. Because I've never written all that down like that on a piece of paper.

By drawing a parallel with counselling, not just a 'regular' session but 'a huge counselling session', Jenny gives us a glimpse into the emotive and embodied experience of the research process, and specifically, of depicting her family on 'paper'. While this quote supports genograms' capacity for therapeutic impact, it also illuminates the possible emotional toll on research participants. It is this potential for instigating a metaphorical opening of Pandora's Box in the research space that carries with it the greatest ethical challenge for researchers wanting to implement genograms. Perhaps these effects are an inevitable consequence of using a therapeutic tool in research. Nonetheless, they necessitate our attention, and demonstrate the need for greater investigation into the impact of using genograms with research participants. 
Isla's Retrospective genogram (see Fig 2.) sheds light on the physical abuse running through the family from the $4^{\text {th }}$ to the $2^{\text {nd }}$ generation.

Figure 2. Extract from Isla's retrospective genogram, identifying intergenerational history of physical violence

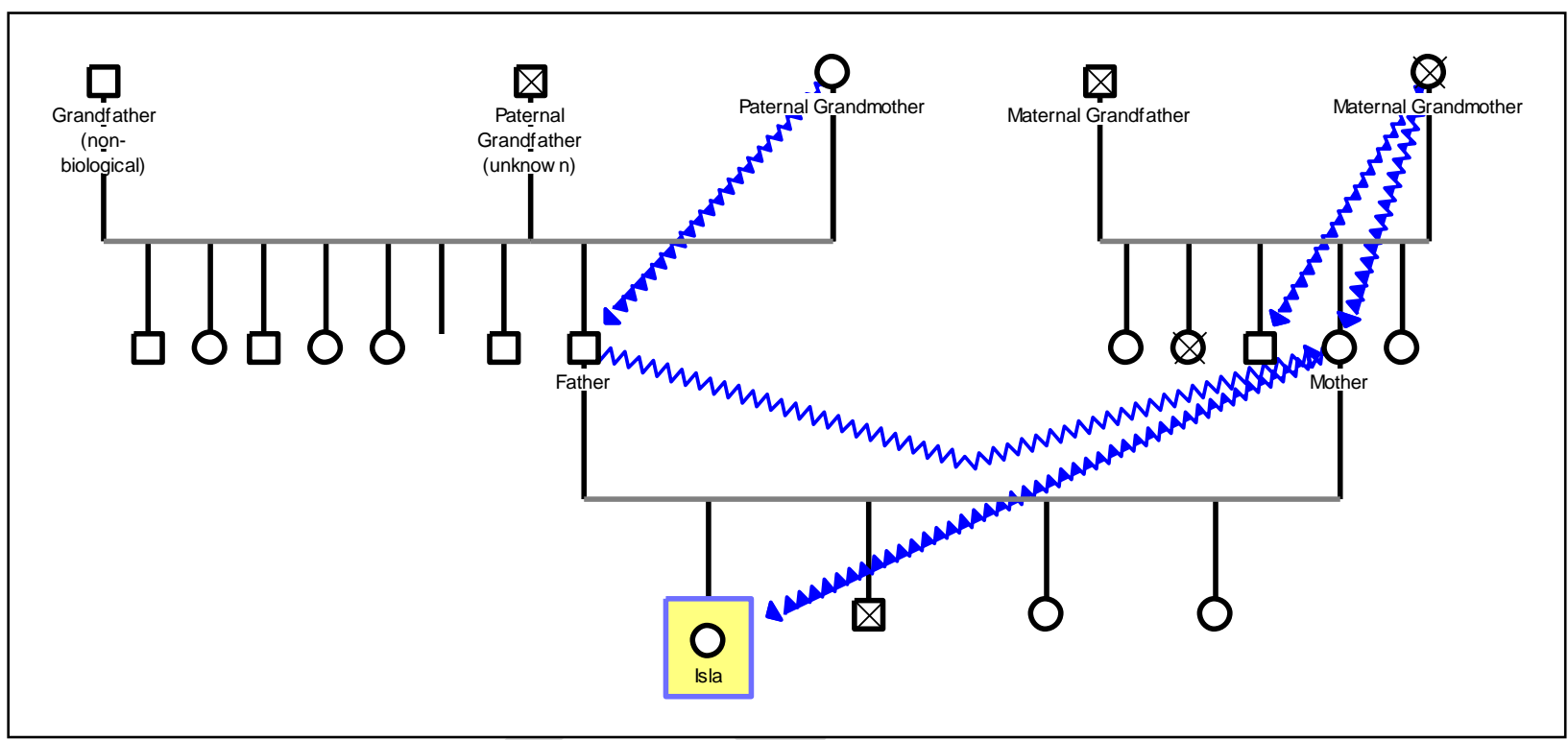

Reflecting on her genograms enabled Isla to link her own behaviours in adulthood with intergenerational patterns in her family-of-origin:

Int: So if we look at all these blue lines (from $4^{\text {th }}$ generation through $2^{\text {nd }}$ ), these are all 'physical abuse'.

Isla: It actually makes me understand why I am like I am, a little bit.

Int: What are you 'like'?

Isla: A bit aggressive. [...] That's the build up, you know. If I get built up and aggressive, I sometimes see that red mist. I haven't done it for a long time but it is literally, if I'm getting arrested, I've actually lost control and attacked whoever's coming towards me. [...] I'm holding it down, but it's scary holding it down because if I've got no release for it, it's going to come out in the wrong way again, and that might happen again.

Here, Isla makes a connection between her behaviours in adulthood and her family's history of physical abuse. This demonstrates an awareness that her response to physical restraint when being arrested in adulthood ('I've actually lost control and attacked whoever's coming towards me') might be linked to her early experiences, perhaps to those which saw restraint on her movement and freedom ('She used to lock me in the cellar', 'I was always locked in my room most of the time'). Engaging with her genogram, elicits a shift, an 'altered perception' (Hartman, 1995) which calls into question her self-identity as 'aggressive'. Instead of locating 'aggression' within herself as an inherent 
personality trait ('like I $\mathrm{am}^{\prime}$ ), she can see it as a co-constructed, congruent response to her family history.

Constructing their genograms, led some of the women to identify one individual as the root cause of the disharmony in their family systems. These revelations were accompanied by a strong sense of injustice and polarised language which represented those identified as wholly malevolent:

Jenny: So when it's down here on paper and you're going, oh my God, and she was abused by him and I was abused by him, and - you know, and he was just evil, my dad was just evil, you can see all the people he's abused, including my auntie in a way.

Depicting her family makes the intangible (and unarticulated) tangible, more concrete, and the 'truth' of this visibility seems incontrovertible, for Jenny. She expresses a sense of shock ('oh my God') at seeing her family symbolically 'on paper', and the renewed perspective of her father that this induced ('he was just evil, my dad was just evil'). Methodologically, genograms seemed to generate new insights from participants which may not have been produced without this kind of visual tool. As such, insights are a co-production, created in the context of the researcher-participant encounter, and in the interactions between participant and methodology.

Echoing Jenny, Sue expressed a similar sense of surprise. Sue's interview was peppered throughout with references to the 'closeness' of her family. Reflecting on the final image of her genogram though, instigated a re-framing, a movement from a narrative about closeness to one which better aligned with the distance represented in her visual depiction:

Int: ... what it was like for you to do the genogram?

Sue: Yeah. The genogram was quite scary actually. Looking back at it now, you think, oh, is this really my family? It's spread out everywhere... and no contact with my younger brother or my older brother, which is very scary because we were a close family when we were much younger. [...] It's just pretty scary really, looking at it all. [...] how somebody can sort of split a whole family up where our family was so close. He split up the whole family.

Rather than inducing a more systemic framing of the family system, sympathetic with all members, Sue's genogram resulted in an identification of one person as pivotal in the damage and dissolution of what she considered to be her 'close family'. Sue's experience of her genogram as 'scary' signals a level of shock at seeing a visual representation in stark contrast with her verbal narrative of 'closeness'. These kinds of contrasts cultivate space in which to explore discrepancies, and generate rich interview data. However, epiphanies, or indeed, the unveiling of 'myths' induced by genograms, illuminates their power to shift realities of relationships (Iverson et al, 2005). The strong expressions of surprise, as expressed by Sue and Jenny, highlight the potential risk of inducing emotional upset or anxiety (Crowell, 2017) when using genograms in sensitive research.

When used in conjunction with interviews, genograms have enormous potential to generate rich qualitative data. They can aid researchers' understandings of family structures and relationships and, as a visual methodology, they make visible the previously unidentified and unarticulated. They highlight discrepancies between family narratives and participants' lived stories and, as a result, can 
lead to renewed insights of self and family. This kind of 'therapeutic effect' presents an ethical challenge, and highlights the risk of inducing lasting effects and emotional responses in research participants.

\section{Simplifying the Complex: The Limitations of Labels}

This theme explores the limitations of genograms in enabling accurate depiction of participants' families, and the struggles that emerged for them in trying to symbolise their complex relationships and histories of violence.

Below, Amy articulates the difficulties of symbolising familial relationships and roles when they subvert normative, hierarchical family structures:

Int: Anything you want to add within these immediate family relationships?

Amy: I haven't really put how I felt, but I don't think there's anything that - because it's such a complicated feeling, and this is where it gets really difficult because I took on a maternal role in that situation but it wasn't necessarily out of love but it was more of a necessity, so maybe I could just make a little note somewhere?

As genograms typically represent genealogies via hierarchical and linear ancestral descent, they risk neglecting different cultural and economic contexts of family that prioritise, or that require- out of necessity, shared family responsibility, community involvement, or the subversion of traditional hierarchical roles, that might more accurately represent 'family' for some (Krause, 1998; Singh, 2009). As they created their genograms, participants tried to navigate these kinds of restrictions to ensure their experiences were made visible, and represented graphically. As Amy discovered, this was not always possible through the symbols alone. In order to circumvent some of the limitations, the research process was flexible, allowing participants to make notes on their genograms, or to date particular interactions, and to communicate this information dialogically in interview.

Depicting ambivalence, a feature of violent relationships (Sammut Scerri, 2015), was also difficult for some of the women:

Amy: I would say my mum was very manipulative, that's how l'd put- I struggle to put down my relationships with other people but-

Int: What do you mean?

Amy: Well, when we were doing this map [...] I was really struggling to - because of how complex my relationships are with people that they could be abusive and loving in the same time, which makes absolutely no sense to anybody who is outside of that situation. How you can love someone who is so horrific to you, and how they can love you, and they do love you, which is the most twisted thing in the whole - as close as they can understand love I suppose. And it's hard to say.

Amy's quote, not only illuminates the limited capacity of genograms to be representative, but also how the process of working through genogram construction can generate valuable research data. In this case, we get a glimpse into the turmoil accompanying ambivalent relationships and we learn that 
Amy's relationships, affected by violence, are counter-hegemonic, and as such, are difficult to articulate lest to label. The frustration of the reductionism of genograms generated data in its own right, provoking participants to further elaborate on the complexity of family relationships, and to identify, navigate, and reconcile the reductionism of their genograms with detailed verbal accounts.

Participants also struggled to represent relationships retrospectively, especially where they considered them to be volatile and unstable over time. For example, Kerry illustrates how family 'truths', dependent on context, are changeable:

Kerry: In a funny kind of way, it would have been really interesting to have done this five years ago, because I think everything I would have said would have been very, very different.[...] I think the reason there's so much unknowables and so much confusion is because the trust in [mother-daughter] relationship has been broken. So a lot of the "truths" - I know about this family picture, even about the abuse my father suffered, all of that is filtered through my mum. Everything I know about my family is via my mum. [...] Which is why it's hard, in a way, to map a particular point in time because it's very hard to put myself back in how I truly felt at that time, because it's hard not to be clouded by what I know now, if that makes sense.

As genograms are generally reflective of a specific time, it is more difficult for them to be fluid, capturing the temporal and transitory nature of family relationships and composition over time. As such, they can be somewhat static, risking the portrayal of family dynamics as a-contextual or 'timeless'. In sensitive research, this risks entrenching unhelpful discourses involving intergenerationality, especially around proclivity to repeat family patterns.

This theme has illustrated that while genograms can generate rich research data, they can also mute the visual depiction of dynamic and rapidly changing relationships, of those that subvert hierarchical structures (such as caring roles), and of ambivalent relationships. Without sufficient symbols or techniques to notate the complexity, variation and transitory nature of family contexts and relationships, especially those counter-hegemonic, we risk disabling the representation of families as participants envisage them. Genograms provide a 'snapshot' of family, and are, to a certain extent, necessarily limited in the information they symbolise. In isolation this 'snapshot' is overly simplistic and reductionist, and presents a difficulty for researchers hoping to analyse genograms in isolation. However, interviews can counter these restrictions by giving participants the opportunity to talk about the difficulties they experienced in trying to symbolise their families. In this way, the restrictions themselves can enrich participants' accounts, allowing them to identify and talk about the tensions between their family-of-origin and normative, depict-able 'family'.

\section{Genograms as Transformative}

This theme represents how some participants, of their own accord, re-created or engaged with genograms outside of the research space. There is some cross-over between this final theme and the first. Both touch upon the ways that genograms impacted on participants; however, this theme explores direct reports from participants about the active ways they used genograms, or insights garnered from construction, outside of the research space. We explore the capacity of genograms to impact on people's lives in the long term, and consider the ethical implications of this for research. 
As a risk-reduction measure, research-related paperwork was restricted and women were made aware that they were not required to carry out any research into their family histories. In spite of this, two of the women informed the interviewer that they had created their own genograms at home, one prior to interview, and the other, in-between sessions. Below, Claire notes the practice run she did with her sister (Candace), the day before her interview:

Int: So it'd be great if you could add your partners in, previous partners.

Claire: (Laughs) Got more paper? Me and Candace done that yesterday with me and my partners. Right.

Int: What did you do?

Claire: She was writing my- from the kids here to the partners...

Like Claire, Sue also created her genogram at home. Sue's re-creation though had more of a purpose - to illustrate to her son's girlfriend (Darcy) the impact her son's father (Bob) had on the family system:

Sue: I don't want to upset you with all this. It's a daunting situation for you, I suppose really, looking at all this.

Int: Well it's interesting for me to listen to your story, as much as you're willing to tell it.

Sue: It is a daunting one for you to look at and you think, oh god, this is a mixed up family. It is a mixed up family but-

Int: Do you think that it's difficult for other people to understand this from the outside?

Sue: Yeah. Yeah. I wanted Darcy to know about it, which is [Son's] girlfriend, and she went, "Cor, I'd like you to do a family tree." I showed her and she went, "Oh, it is a bit-"

Int: So you did your own family tree for her?

Sue: Yeah, and she went sort of, "Oh my goodness!" [...] but I didn't put all these lines to say who hated who. But this was all my line and she went, "Oh, how weird is that."

Int: So it sounds like it's important for you to speak about it and show people what's happened.

Sue: I do because, at the end of the day, I would never have turned round to Darcy and said, "Stay in the house with Bob on your own. Go to the house on your own." I've got to make sure somebody's there.

Showing her 'family tree' to her son's girlfriend gives Sue a way of articulating the danger of Bob, her worries about Darcy being in the house alone with him, a worry she 'would never have said'. Her genogram then becomes a powerful non-verbal tool which supports her indirect dialogical communication of the history and of her concerns. 
Taking part in the study inspired both Claire and Sue to engage with their histories through the partial (re-)creation of their genograms. By constructing them outside of the research space, it enabled both women to connect with their 'family' members in ways they may otherwise not have done without participation in the study. This is an unintentional effect of the research that enables us to envisage how using genograms can elevate risk.

Two participants felt that their first interviews were transformative and instigated new ways of relating with family members. Below, Kerry suggests that her genogram made her more conscious of the distance that had grown between her and her family, which allowed her to actively foster those relationships, on her terms:

Kerry: I think what happened in the previous interview is it really made me think, actually, my family are slowly getting more and more distant because we're not effectively coping with what happened in various ways. And actually, if we continue to let that happen, we're going to lose each other completely. So I think what happened was I started to try to make conscious decisions about what I wanted from these relationships. And also to try and forge them on my own terms, regardless of what went before or the fact that abuse has run through my family on both sides for now three generations, that actually effectively l've got agency in this now to choose what I allow to affect me and what I don't. [...] I'm trying to deal with each person individually and not get caught - because this is a hell of a web, like you could easily get enmeshed in all of these complicated lines between each person. And what I'm trying to do is not do that and just deal with each person for who they are, with all their foibles. And also try not to let it get to me personally. I think what this process showed me is it's almost like everyone is dealing with their own shit, if you pardon me using the word, but it kind of is what it is. [...]So in a funny kind of way it started the process of being able to separate my identity perhaps from the messiness of this (laughs) that's going on.

The research process seemed to be especially meaningful for Kerry, giving her a reflex space in which to take stock of relationships and to envision and instrument a rebuilding of relationships. Further, she implies that engagement with her genogram triggered a sense of empathic understanding and an acceptance of family members' difficulties. Her renewed perspective establishes her as part of the family, but not bound by it, not defined by its history. More importantly though, is the empowered way she positions herself, as an agent for more fulfilling, and healthy relationships. Discussing the use of genograms and ecomaps in social work practice, Iverson et al (2005) maintain that they can '... challenge the delimiting realities of the present and open up new possibilities for understanding and action.' (p.16). Similarly, Rempel et al., (2007) propose that genograms and ecomaps can uncover unrealised potential in family systems and social networks. Kerry's quote indicates that in research, even in one-off encounters, genograms can similarly uncover potential and instigate participants' renewed understandings of self and other, and alternative ways of relating.

Similarly, Bettina maintains that since participation in the study, the relational dynamics in the mother-daughter relationship altered:

Bettina: ... when I came on the research and was able to talk with my mother, now something changed. [...] I talk with my mother and I tell everything. And she doesn't like it still because she still tries to control, but when before I was calling and she would put me down and I was 
always upset when I put the phone down, now I don't care, it's out. What [she says doesn't] touch me anymore.

Int: [...] You say what you want to say?

Bettina: That's it. Gone. I sleep nicely (laughs). I don't worry. I don't cry. I don't- No. Before I was more, hmm, "why did she say that, why is she saying that?", you know?

Perhaps like Kerry, Bettina's engagement with her family's history inspired a more systemic envisioning of the family, and with it, an understanding that all members are navigating their own difficulties. While Bettina's quote speaks of finding strength and feeling empowered, it highlights how investigating personal aspects of people's lives might remain with them and in effect beyond the researcher-participant encounter, leading to marked changes in their lives. This theme demonstrates the ways that genograms (or insights garnered) spilled outside of the research space and into the lives of participants. These are the kinds of therapeutic effects that genograms would be used to promote in therapeutic practice. In the context of research though, they are in essence a disruption, unintended effects that we may not be prepared for as researchers. This gives us insight into the therapeutic power of genograms, of the ethical complexities of applying a therapeutic tool in research, and highlights the need for further investigation into the possible impacts on research participants.

\section{Discussion}

Genograms are used in therapeutic practice to promote clients' deeper reflection, elicit renewed understandings of self and family, and to identify alternative ways of relating (Mackay, 2015; McGoldrick et al., 2008). They enhance the therapeutic alliance, developing client-therapist rapport and trust, and contextualising the client's lived experience of the micro system (Altshuler, 1999; Burley, 2014; Mackay, 2015). Despite gaining traction as a research tool, the literature exploring participants' experiences of engaging in the genogram process is limited. This paper contributes to this literature by providing insight into the experiences of a small cohort of research participants.

The cohort of women were recruited to participate in a qualitative study investigating the intergenerational transmission of family violence. This study included a small $(n=9)$ and specific sample of women who identified as having experienced family violence in multiple generations. The women had contact with formal domestic violence or counselling services, or non-formal support systems (such as peer-support and church groups), where they had experience of reflecting on and talking about their histories of violence and intimate relationships. This study required participants to share personal aspects of their lives, and as such, it likely attracted a particular cohort of women, who had experience of and were keen to engage in their family histories.

As a visual method, genograms provided the women with a material object through which to indirectly express 'difficult memories and powerful emotions' (Prosser, 2013, p.188). They helped to anchor interviews, to contextualise participants' within their micro systems, and prevented participants from having to provide long-winded descriptions of family members and their position/relationship to others. The generative capacity of genograms was a prominent feature of this study, and used in conjunction with interviews, produced a wealth of rich data which could not have been generated using interviews alone. While participants in this study expressed feeling restricted by the reductionist 
labels of genogram construction, interviews enabled them to provide detailed accounts which expanded on their genograms, and explored tensions and consistencies between actual and symbolised family.

This paper illustrates the numerous ethical challenges that genograms bring to the context of research. While the women in this study reflected on their engagement in the genogram process in predominantly positive ways, it is also evident that constructing their genograms had unintended therapeutic effects, induced a deep level of reflection on family history, and transformed the ways they envisaged and understood themselves, their family members, and the role of violence within their family system. These transformative effects (altered perception and renewed insights) transcended the interview room, out of the control of researchers, and into participants' lives. This signals a blurring of the boundaries between clinical and research impact, and troubles the idea that research, such as this, which explores highly personal material, remains within the researcherparticipant encounter. This locates genograms as an ethical challenge for researchers wanting to use them, and highlights the need for further investigation into their application in research.

\section{Conclusion}

When used in research, genograms present a range of ethical challenges that necessitate researchers' attention. The transformative effects reported by participants involved in this study highlight the potential for genograms to elicit emotional responses when used in research. In order to reduce the risk of emotional distress, we provide five key recommendations for researchers wanting to use genograms:

Firstly, we suggest that researchers are explicit about the potential therapeutic effects of participation in studies involving genograms, particularly around their capacity to elicit renewed understandings of self and family and, as a result, to induce strong emotional responses.

Secondly, researchers should ensure that participants either have existing contact with support agencies, or are able to access support if necessary. Genogram studies may attract participants interested in connecting with their histories, or in understanding more about the 'patterns' that they have already observed within their families. In sensitive research, it will be especially important that they are able to access onward emotional support to explore issues brought to the fore by the research. In this case, following participation, several of the women showed a desire to access specialist emotional support (e.g. for DV and rape). While the research did not initiate this need, it did centralise it as an issue for the women's attention. As such, it was important that the field researcher was aware of appropriate services, and could signpost/refer participants as and when they were ready to access support.

Genogram construction is time-consuming, for this reason, this study was designed to be flexible enough to enable women to break down the visual method/interview process, or to have follow-up interviews over a number of sessions. This allowed women to have a break between sessions, facilitated a sense of rapport, and better captured the complexities and transitory nature of 
relationships. The structure and duration of data collection sessions requires careful consideration from researchers to prevent over-taxing participants.

We recommend researchers make the limitations of genograms explicitly clear to participants at three points; prior to consent, during construction, and in debrief. This is with a view to preventing participants construing their genograms as a 'map' of their family past, present and future. In sensitive research, in particular, envisioning proclivity to repeat family patterns could prove incredibly distressing to participants. Explaining the limitations around the genogram's lack of ability to represent extra-normative family compositions and temporality, would be especially helpful in establishing a sense of the inherent issues of symbolising family.

Finally, we suggest that researchers consider alternative ways that participants might represent their families beyond biology and hierarchy, whether this is through graphic of textual notation, or verbalised in interview.

\section{References:}

Altshuler, S. J. (1999). Constructing genograms with child in care: Implications for casework practice. Child Welfare, 78(6), 777-790.

Banks, M. (2012). The place of visual data in social research: A brief history (pp. 81-96). In: Hughes, J. (Ed) SAGE Visual Methods. London: Sage.

Bunnell, S. L., \& Legerski, J. P. (2010). The Risks, Benefits, and Ethics of Trauma-Focused Research Participation. Ethics \& Behavior, 20(6), 429-442.

Burley, C. J. (2014). Therapists' experience of using the genogram in systemic family and couples therapy (Doctoral dissertation, University of Exeter).

Carter-Visscher, R. M., Naugle, A. E., Bell, K. M., \& Suvak, M. K. (2007). Ethics of asking trauma-related questions and exposing participants to arousal-inducing stimuli. Journal of Trauma \& Dissociation, $8(3), 27-55$.

Castoldi, L., Lopes, R. D. C. S., \& Prati, L. E. (2006). The genogram as a research instrument of the impact of stressful events in the family-school transition. Psicologia: Reflexão e Crítica, 19(2), 292-300.

Congress, E. P. (1994). The use of culturagrams to assess and empower culturally diverse families. Families in Society, 75, 531-539.

Crowell, J. H. (2017). Teaching Note-Fostering Political Awareness in Students Through the Use of Genograms. Journal of Social Work Education, 1-6.

Frost, N. A., \& Nolas, S. M. (2011). Exploring and expanding on pluralism in qualitative research in psychology. Qualitative Research in Psychology, 8(2), 115-119 
Hardy, K. V., \& Laszloffy, T. A. (1995) The cultural genogram: key to training culturally competent family therapists. Journal of Marital and Family Therapy, 21, 227-237.

Hartman, A. (1995). Diagrammatic assessment of family relationships. Families in Society, 76(2), 111122.

Iverson, R.R., Gergen, K.J., \& Fairbanks II, R.P. (2005). Assessment and Social Construction: Conflict or Co-Creation? British Journal of Social Work, 35, 1-20.

Keiley, M. K., Dolbin, M., Hill, J., Karuppaswamy, N., Liu, T., Natrajan, R., Poulsen, S., Robbins, N., \& Robinson, P. (2002). The cultural genogram: Experiences from within a marriage and family therapy training program. Journal of Marital and Family Therapy, 28(2), 165-178.

Krause, I.B. (1998). Perspectives on psychotherapy. Therapy across culture. Thousand Oaks, CA: Sage Publications.

Leonidas, C., \& Santos, M. A. (2015). Family relations in eating disorders: the Genogram as instrument of assessment. Ciencia \& saude coletiva, 20(5), 1435-1447.

Mackay, B. (2015). Genograms or "housework". New Zealand Journal of Counselling, 35(2).

McGoldrick, M. (2016). The Genogram Casebook: A Clinical Companion to Genograms. New York: W.W. Norton and Company, Inc.

McGoldrick, M., Gerson, R., \& Petry, S. (2008). Genograms: Assessment and Intervention (Third Edition). London: W.W. Norton and Company, Inc

Milewski-Hertlein, K. A. (2001). The use of a socially constructed genogram in clinical practice. American Journal of Family Therapy, 29(1), 23-38.

Mitchell, C., Theron, L., Stuart, J., Smith, A., \& Campbell, Z. (2011). Drawings as research method. In: Theron, L., Mitchell, C., Smith, A., \& Stuart, J. Picturing research: Drawing as Visual Methodology, (pp.19-36). Boston: Sense Publications

Piedra, L. M. (2016). In this issue... shady edges worth preserving. Qualitative Social Work, 15(4), 457461.

Poulsen, S.S. (2017) Expanding Conversations about Cultural Responsiveness in Supervision. In: Allan R., Singh Poulsen S. (eds) Creating Cultural Safety in Couple and Family Therapy, (pp.23-32). AFTA Springer, Cham.

Prosser, J.D. (2013) Visual Methodology: Toward a More Seeing Research. In: Denzin, N.K., \& Lincoln, Y.S. (Eds) Collecting and Interpreting Qualitative Materials (4 $\left.{ }^{\text {th }} \mathrm{Ed}\right),(\mathrm{pp} .177-212)$. London: Sage Publications Ltd 
Rempel, G.R., Neufeld, A., \& Eastlick Kushner, K. (2007). Interactive Use of Genograms and Ecomaps in family Caregiving Research. Journal of Family Nursing, 13(4), 403-419.

Rohrbaugh, M., Rogers, J. C., \& McGoldrick, M. (1992). How do experts read family genograms?. Family Systems Medicine, 10(1), 79.

Sammut Scerri, C. (2015). Living with contradictions of love and violence: a grounded theory study of women's understanding of their childhood experiences of domestic violence (Doctoral dissertation, University of Surrey).

Singh, R. (2009). Constructing 'the family' across culture. Journal of Family Therapy, 31(4), 359-383.

Sullivan, C. M., \& Cain, D. (2004). Ethical and safety considerations when obtaining information from or about battered women for research purposes. Journal of Interpersonal Violence, 19(5), 603-618.

Tasker, F., \& Granville, J. (2011). Children's views of family relationships in lesbian-led families. Journal of GLBT family studies, 7(1-2), 182-199.

Watts, C., \& Shrader, E. (1998). How to do (or not to do)... The genogram: a new research tool to document patterns of decision-making, conflict and vulnerability within households. Health Policy and Planning, 13(4), 459-464.

Watts-Jones, D. (1997). Toward an African American genogram. Family Process, 36(4), 375-383.

Werner-Lin, A., \& Gardner, D.S. (2009). Family illness narratives of inherited cancer risk: Continuity and transformation. Families, Systems, \& Health, 27(3), 201-212

Appendix 1. Participant Table

\begin{tabular}{|l|l|c|l|}
\hline $\begin{array}{l}\text { Participant } \\
\text { No. }\end{array}$ & Pseudonym & Age & Ethnicity \\
\hline $\mathbf{1}$ & Kerry & 28 & White British \\
\hline $\mathbf{2}$ & Bettina & 45 & Italian \\
\hline $\mathbf{3}$ & Naomi & 22 & White British \\
\hline $\mathbf{4}$ & Jenny & 50 & White British \\
\hline $\mathbf{5}$ & Isla & 47 & White British \\
\hline $\mathbf{6}$ & Georgia & 26 & White British \\
\hline $\mathbf{7}$ & Sue & 46 & White British \\
\hline $\mathbf{8}$ & Claire & 31 & White British \\
\hline $\mathbf{9}$ & Amy & 31 & White British \\
\hline
\end{tabular}

